Article

\title{
Broad-Scale Environmental Conditions Responsible for Post-Fire Vegetation Dynamics
}

\author{
Grant M. Casady ${ }^{1, *}$ and Stuart E. Marsh $^{2}$
}

1 School of Natural Resources and the Environment, University of Arizona, Tucson, AZ 85721, USA

2 School of Natural Resources and the Environment and School of Geography and Development, University of Arizona, Tucson, AZ 85721, USA; E-Mail: semarsh@email.arizona.edu

* Author to whom correspondence should be addressed; E-Mail: gcasady@email.arizona.edu; Tel.: +1-520-621-3694; Fax: +1-520-621-7834.

Received: 29 September 2010; in revised form: 10 November 2010 / Accepted: 22 November 2010 / Published: 25 November 2010

\begin{abstract}
Ecosystem response to disturbance is influenced by environmental conditions at a number of scales. Changes in climate have altered fire regimes across the western United States, and have also likely altered spatio-temporal patterns of post-fire vegetation regeneration. Fire occurrence data and a vegetation index (NDVI) derived from the NOAA Advanced Very High Resolution Radiometer (AVHRR) were used to monitor post-fire vegetation from 1989 to 2007 . We first investigated differences in post-fire rates of vegetation regeneration between ecoregions. We then related precipitation, temperature, and elevation records at four temporal scales to rates of post-fire vegetation regeneration to ascertain the influence of climate on post-fire vegetation dynamics. We found that broad-scale climate factors are an important influence on post-fire vegetation regeneration. Most notably, higher rates of post-fire regeneration occurred with warmer minimum temperatures. Increases in precipitation also resulted in higher rates of post-fire vegetation growth. While explanatory power was slight, multiple statistical approaches provided evidence for real ecological drivers of post-fire regeneration that should be investigated further at finer scales. The sensitivity of post-disturbance vegetation dynamics to climatic drivers has important ramifications for the management of ecosystems under changing climatic conditions. Shifts in temperature and precipitation regimes are likely to result in changes in post-disturbance dynamics, which could represent important feedbacks into the global climate system.
\end{abstract}

Keywords: AVHRR; CART; climate change; disturbance; NDVI; time-series; wildfire 


\section{Introduction}

Ecosystem response to disturbance is a function of factors interacting within and across a variety of scales $[1,2]$. For terrestrial ecosystems changes in climate represent a shift in high-level constraints on ecosystem behavior. Natural resource management decisions are often predicated on a perception that future ecosystem behavior can be anticipated based on past dynamics. It is therefore essential to understand the influence of broad-scale environmental constraints on post-disturbance ecosystem dynamics.

Recent research indicates that changes in high-level climate constraints have resulted in shifts in historic fire regimes [3,4], leading to increases in the frequency and severity of fire disturbance worldwide [5-8]. These forces are also likely to result in changes to post-fire vegetation dynamics. While research has been done regarding local factors that influence post-fire response [9-11], little has been done to assess the influence of climate on post-fire dynamics. We used an 18 year time-series of satellite vegetation data to monitor post-fire vegetation across the western US, and related post-fire vegetation trends to climate variables to determine the influence of these factors on post-fire vegetation.

While post-disturbance vegetation communities typically follow a trend of increasing productivity, various forces define the specifics of the post-disturbance response [1]. To evaluate variations in post-fire response we used satellite based vegetation data to estimate primary production following fire events across the western US. Satellite-based vegetation indices (VIs) are useful for indicating relative rates of primary production [12,13], and can monitor temporal changes in vegetation over time and across large areas $[14,15]$. Several studies have established the value of using time-series VI data to evaluate post-fire response for fires occurring over large areas [16-18].

\section{Goals and Hypotheses}

One goal of this research was to evaluate time-series satellite based VI for monitoring post-fire vegetation dynamics across the western US. We used an extensive fire database and a time-series of NOAA Advanced Very High Resolution Radiometer (AVHRR) VI data to measure post-fire vegetation. As a proxy for production, a time-series of Normalized Difference Vegetation Index (NDVI) data was used to monitor post-fire vegetation for 443 large fires occurring from 1989 to 2003. Vegetation was monitored from the time of each fire through June of 2007. Using these data we evaluated three hypotheses:

$\mathbf{H}_{1}$ : The slope of the post-fire NDVI time-series will be positive, indicating increasing productivity over time.

A second goal was to evaluate the influence of environmental factors on trends in post-fire vegetation. First, we evaluated post-fire regression slopes for western US ecoregions. We used a scheme developed by Bailey [19] to compare post-fire vegetation at several scales and test our second hypothesis:

$\mathbf{H}_{2}$ : There are differences in the slope of the post-fire NDVI time-series between ecoregions, with differences being more prevalent at some levels in the hierarchy than at others. 
Next we evaluated post-fire vegetation trends in terms of regional scale climate averages to investigate the drivers responsible for differences in post-fire vegetation. We hypothesized that:

$\mathbf{H}_{3}$ : Temperature and precipitation regimes serve as broad-scale factors that are responsible for variability in post-fire vegetation dynamics.

\section{Materials and Methods}

Determining post-fire trends in vegetation required the acquisition of historical fire locations and measurements of post-fire vegetation. Fire locations were derived from a database developed from federal agency records and maintained by the Desert Research Institute (DRI) [20]. Vegetation measurements were obtained using $1 \mathrm{~km}$ resolution AVHRR Maximum Value Composite (MVC) NDVI data, available every 14 days from 1989 to 2007 [15]. AVHRR data were obtained from the USGS Land Processes Distributed Active Archive Center (LP DAAC).

\subsection{Selecting fires from the DRI database}

In 2002 DRI reported on an inter-agency fire database dating to 1970, gathered from federal agencies in the United States, and evaluated for accuracy [20]. Brown et al. [20] caution that the coarse nature of their analysis may leave many errors uncorrected in fire location, date, and extent due to discrepancies in the recording of fire events. As most of the US federal lands are located in the western US, we restricted our analysis to areas west of $100^{\circ}$ longitude west.

Description of post-fire vegetation required confidence regarding the location of burned pixels in the AVHRR data. While the omission of any particular burned pixel was acceptable, our study required that pixels identified as burned had in fact burned. We therefore filtered the DRI database using a four step process. First, we limited the dataset to the continental US, excluding Alaska, to match the extent of the AVHRR MVC data. Second, only fires large enough to comprise multiple AVHRR pixels were included, using a threshold of $10 \mathrm{~km}^{2}$, or at least ten AVHRR pixels.

Third, the AVHRR data were used to investigate the vicinity of each of the remaining 3,198 reported fires for evidence of burn scars. Since fire locations were expressed as a point location, a search area was defined for each fire by buffering the fire location point with a circle of twice the reported burned area from the DRI database (Figure 1). This area was selected such that it was small enough to reduce the likelihood of including unburned pixels in the search, yet large enough to allow for enough search area to include sufficient burned pixels given the size of the burn. Within each search area, the AVHRR composite period subsequent to each recorded fire event was subtracted from the period prior to the event, assuming that fire events result in reduced NDVI. 
Figure 1. Work flow for the selection of fires meeting the minimum burned area criteria of $10 \mathrm{~km}^{2}$. Fire locations in the DRI database $(\mathrm{n}=3,198)$ were buffered with a circular area twice that of the reported burned area. This example shows the Fountain Fire (August 1992 east of Redding, California). The fire was reported in period i (b). A z-score was calculated for the difference between periods $i-1$ and $i+1 \mathbf{( a , c )}$ relative to the average differences between two periods $j-1$ and $j+1$ across the time-series. If the z-score of a pixel exceeded the threshold of 1.65 , and a contiguous group of six such pixels existed, the fire was included in the analyses, and a polygon establishing the perimeter of the fire was created (d). The polygon was then used to define an area within which to calculate the average for each period of AVHRR NDVI data from January 1989 to June 2007 (e). These data were summarized by summing the NDVI values for each post-fire year (26 AVHRR periods) in the record (e). These summaries were then used in regression equations to establish relationships between post-fire trends and broad-scale environmental drivers.

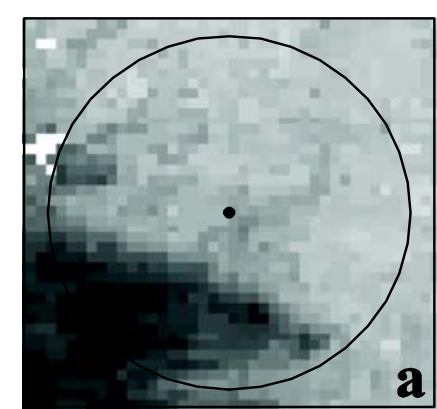

NDVI $(i-1)$

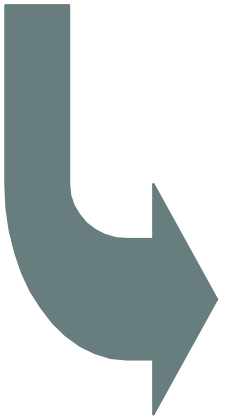

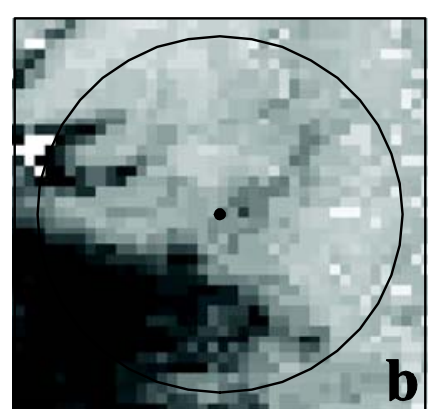

NDVI $(i)$

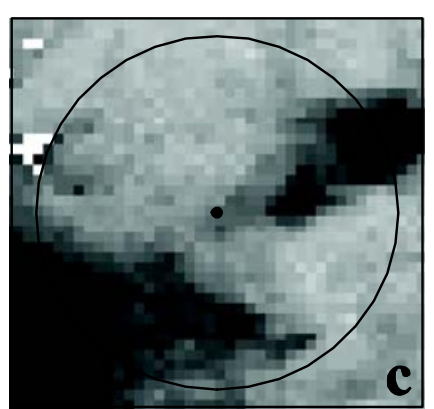

NDVI $(i+1)$
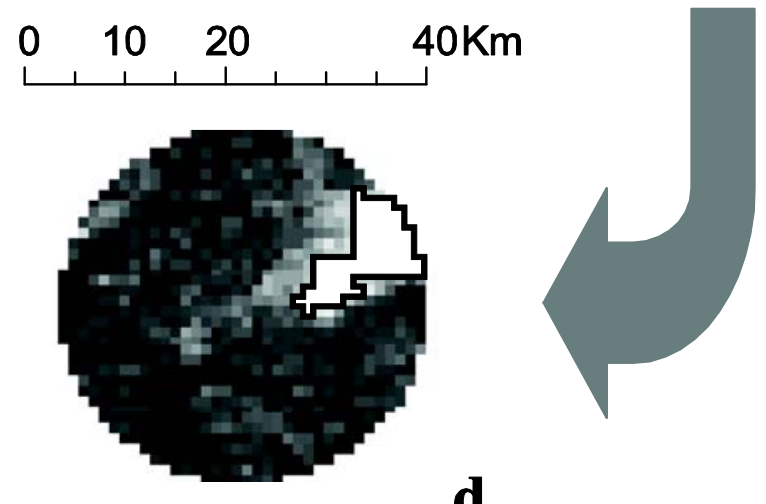

d

$z$ - score

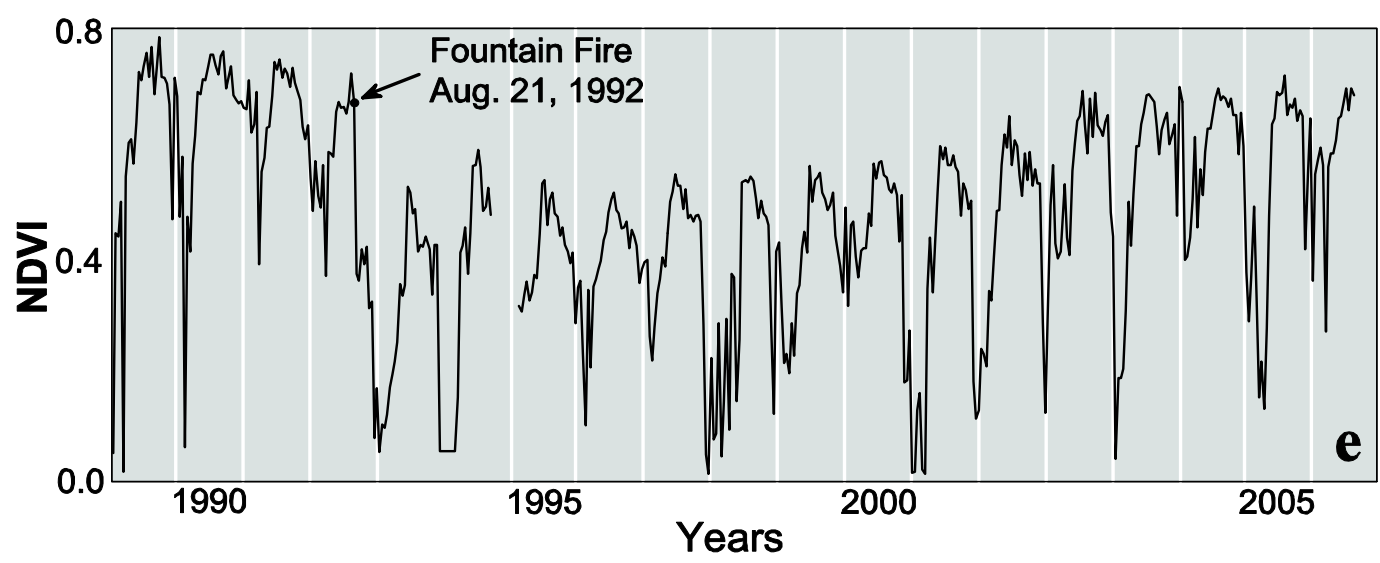


A threshold was then set using the z-score of the difference following a modified version of a technique proposed by Yool [21]. The z-score was calculated for each pixel as:

$$
z=\frac{x\left(p_{i-1}-p_{i+1}\right)-\bar{x}\left(p_{j-1}-p_{j+1}\right)}{s\left(p_{j-1}-p_{j+1}\right)}
$$

where $x\left(p_{i-1}-p_{i+1}\right)$ is the difference between NDVI values for pixels ( $\left.\mathrm{p}\right)$ at periods $i-1$ and $i+1$, where $i$ is the period during which the fire occurred, $\bar{x}\left(p_{j-1}-p_{j+1}\right)$ is the average of all such differences for all time periods $j$, and $s\left(p_{j-1}-p_{j+1}\right)$ is the standard deviation of the differences over all time periods $j$.

The result was the standardized degree to which the post-fire to pre-fire difference deviated from the average difference that one would expect in the absence of fire. A threshold of $z=1.65$ was established through visual examination of fires with known fire extents such that pixels that were clearly burned within known burn perimeters were included and ambiguous pixels were not. Pixels with z-scores $>1.65$ were included in the analysis. These results were refined by selecting the largest group of contiguous pixels within the search area that included $>6$ pixels. This threshold was used because the geolocation of AVHRR pixels is estimated as plus or minus one pixel, thus the 6 pixel area increases the likelihood of obtaining a sample that contained the burned area across the entire time series. The burned perimeter was described as the outline of the selected pixels.

Large fires often burn across several federal jurisdictions, and are often recorded by each agency, resulting in multiple records in the DRI database. We examined each fire and removed fires that had overlapping perimeters. Finally, only fires with at least four years of post-fire NDVI were included in the analysis. After accounting for these final criteria, the number of sites used in the analysis was 443 .

\subsection{Calculating trends in post-fire NDVI}

For each selected site we calculated a time-series of mean NDVI values by averaging the values of all pixels identified as burned for a given site for each step in the NDVI time-series from January 1989 to June 2007. The AVHRR MVC composite period of 14 days results in 26 periods per year, for a total of 484 periods in our time-series, excluding data that were missing due to a data gap between the failure of NOAA-11 AVHRR and the beginning of NOAA-14 AVHRR (September of 1994 through January of 1995). The mean NDVI values were then summed across each 26 period (one year) time step starting from the period immediately after the burn. This resulted in a series of annually integrated NDVI measures starting from the year after the burn and continuing to June 2007. Fires which occurred in 1989 have 18 years of annually integrated NDVI measures, whereas fires occurring in 2003 have only four years of post-fire NDVI data.

Post-fire trends were evaluated by regressing the integrated NDVI on time since burn using the simple linear regression (SLR) model

$$
\int N D V I=\beta_{0}+\beta_{1} \text { year }
$$

where $\int N D V I$ is the integrated post-fire NDVI for each fire, and year is the number of years since burn. A least squares estimate of $\beta_{1}$ and associated $\mathrm{p}$-value for the test that the slope of the relationship $\left(\beta_{1}\right)$ was significant was established for each of the 443 sites. 
Since the study relied on the ability to relate the slope of the integrated NDVI time-series to climate variables, we used only those sites for which we could be confident of the estimate of $\beta_{1}$. The use of AVHRR data to monitor post-disturbance production over time can be problematic due to sources of variation in recorded NDVI resulting from factors other than changes in production. Sources of such noise include snow and ice cover, atmospheric anomalies, and changes in processing algorithms over the course of the time series. It was therefore necessary to be statistically rigorous, and we analyzed only those records that showed either positive or negative regression slopes that were statistically significant $(\alpha<0.05)$. This reduced the final number of fires evaluated in this study to 115 .

\subsection{Evaluation of hypotheses}

$H_{1}$ : Evaluating post-fire regression slopes. To test that post-fire NDVI trends were positive, sites with significant regression slopes were tested using a one sided p-value based on the t-distribution, by testing that the average slope of the post-fire NDVI time-series was greater than zero $(\alpha<0.05)$.

$\mathrm{H}_{2}$ : Evaluating Bailey's Ecoregions. In Bailey's ecoregion classification [19], each level in the hierarchy is nested in the next higher level. Bailey's highest level of classification, the ecoregion, was divided into three levels, with the Domain being the highest level, followed by the Division and the Province (Table 1). The delineation for Domains was based on broad-scale differences in precipitation and temperature. Divisions were separated by finer scale climate considerations, and divided into Provinces based on differences in land cover.

ANOVA was used to evaluate differences in post-fire slopes of NDVI between ecoregions at three scales. Tukey-Kramer's multiple comparison procedure [22] was used to determine differences at the Domain, Division, and Province levels. Such differences are useful in visualizing geographic patterns in post-fire response, however they do not suggest mechanisms responsible for those patterns. Analysis of specific environmental drivers was therefore performed in order to evaluate patterns in post-fire vegetation trends.

$\mathrm{H}_{3}$ : Evaluating environmental factors. Environmental factors were separated into regional and local factors (Table 2). These were analyzed separately in order to avoid multicolinearity between factors in regression analyses and ascertain the influence of environmental factors on post-fire vegetation dynamics at different scales. Both regional and local factors as defined here are broad-scale influences on post-fire vegetation dynamics given that they are averaged across the burned site, and summarized over multiple seasons. Regional factors consisted of 30 year average climate data, which vary gradually across large areas and over long periods of time. Local data included monthly weather data, which often deviate from climatic norms, and can be more variable in both space and time. Elevation was also included as a local factor and served as a potential proxy for localized differences in temperature and precipitation. 
Table 1. Bailey's ecotypes for the Western United States, including the Domain, Division, and Province levels.

1. Dry Domain

11. Temperate Desert Division

1101. Intermountain Semi-Desert and Desert Province

1102. Intermountain Semi-Desert Province

12. Temperate Desert Regime Mountains Division

1203. NV-UT Mountains-Semi-Desert-Coniferous Forest-Alpine Meadow Province

13. Temperate Steppe Division

1304. Great Plains Steppe Province

1305. Great Plains-Palouse Dry Steppe Province

14. Temperate Steppe Regime Mountains Division

1406. Black Hills Coniferous Forest Province

1407. Middle Rocky Mountain Steppe-Coniferous Forest-Alpine Meadow Province

1408. N. Rocky Mountain Forest-Steppe-Coniferous Forest-Alpine Meadow Province

1409. S. Rocky Mountain Steppe-Open Woodland-Coniferous Forest-Alpine Meadow Province

15. Tropical/Subtropical Desert Division

1510. American Semi-Desert and Desert Province

1511. Chihuahuan Semi-Desert Province

16. Tropical/Subtropical Regime Mountains Division

1612. AZ-NM Mountains Semi-Desert-Open Woodland-Coniferous Forest-Alpine Province

17. Tropical/Subtropical Steppe Division

1713. Colorado Plateau Semi-Desert Province

1714. Great Plains Steppe and Shrub Province

1715. SW Plateau and Plains Dry Steppe and Shrub Province

2. Wet Domain

28. Marine Division

2816. Pacific Lowland Mixed Forest Province

2817. Cascade Mixed Forest-Coniferous Forest-Alpine Meadow Province

29. Mediterranean Division

2918. CA Coastal Chapparral Forest and Shrub Province

2919. CA Dry Steppe Province

30. Mediterranean Regime Mountains Division

3020. CA Coastal Range Open Woodland-Shrub-Coniferous Forest-Meadow Province

3021. Sierran Steppe-Mixed Forest-Coniferous Forest-Alpine Meadow Province

\subsubsection{Evaluating regional factors}

We evaluated four regional environmental factors individually and in combination to determine how post-fire vegetation trends are influenced by regional conditions. Temperature and precipitation 
data were derived from the Parameter-elevation Regressions on Independent Slopes Model (PRISM) dataset [23], which includes 30 year average (1971-2000) data for the average daily high and low temperatures for each month, modeled across the United States at a resolution of 30 arc-seconds ( $\sim 800 \mathrm{~m})$. We resampled the data to $1,000 \mathrm{~m}$ and calculated the maximum of the average daily high data (MaxT) and minimum of the average daily low data (MinT) values for each pixel. We then calculated the mean for all pixels within the burn perimeter of each fire. This established temperature extremes experienced by each site. Similarly, the PRISM dataset includes modeled 30 year average precipitation totals for each month. These were summed to obtain an average annual total precipitation per pixel (PPTtotal). The monthly precipitation totals were also used to develop an estimate of the precipitation that falls from April through September (PPTsummer).

Relationships between the regional environmental factors and the post-fire NDVI trends were evaluated using linear regression and regression trees. The relationships between each of the four regional predictors (Table 2) and the response were first evaluated individually using SLR. Next, a full model was fit for NDVI using all four predictors:

$$
\text { slope }=\beta_{0}+\beta_{1} \operatorname{MaxT}+\beta_{2} \operatorname{MinT}+\beta_{3} P P T_{\text {total }}+\beta_{4} P P T_{\text {summer }}
$$

and evaluated using multiple linear regression (MLR). A stepwise evaluation procedure was used beginning with an empty model, where terms were added to the model if they were significant at $\alpha=0.05$, and dropped from the model if their contribution to the model was not significant at $\alpha=0.1$. An inherent challenge with this approach is the collinearity of many of the terms included in the MLR analysis. This is addressed in part by evaluating each term individually, and in part through the use of a non-parametric alternative. Using multiple statistical approaches provided a burden of statistical evidence that could be examined to determine the importance of the factors evaluated for determining rates of post-fire recovery.

Table 2. Factors tested for their relationship with post-fire changes in NDVI and SD for fires across the western United States. Local scale precipitation and temperature data were summarized over one, five, and ten years, and thus three levels of each of these variables were tested.

\begin{tabular}{lll}
\hline Factor & Scale & Description \\
\hline MaxT & Regional & Maximum of the 30 yr average (1970-2000) monthly average highs \\
MinT & Regional & Minimum of the 30 yr average (1970-2000) monthly average lows \\
PPT $_{\text {total }}$ & Regional & Average total annual precipitation from 1970 to 2000 \\
PPT $_{\text {summer }}$ & Regional & Average percent precipitation from April to September 1970-2000 \\
PPT $_{\text {yr }}$ & Local & Cumulative precipitation 1, 5, and 10 years post fire \\
MaxT $_{\text {yr }}$ & Local & Maximum monthly high temperature 1, 5, and 10 years post-fire \\
$\operatorname{MinT}_{\text {yr }}$ & Local & Minimum monthly low temperature 1,5, and 10 year post-fire \\
Elev & Local & Average elevation across the burned site \\
\hline
\end{tabular}

As a non-parametric alternative to MLR, classification and regression trees (CART) were used to evaluate the relationship between post-fire NDVI and the environmental factors [24]. We used CART to evaluate two models using the slope of the post-fire NDVI as a response. The first model used the 
same explanatory variables used in the MLR analysis. The second model used Bailey's ecoregions at the Division level in addition to the environmental variables used in the first model. We pruned the resulting trees using a cross-validation procedure using each of ten subsets in turn to calculate the error (cost) of the tree developed from the remaining nine subsets [24].

\subsubsection{Evaluating local factors}

We considered monthly precipitation and temperature records as local factors, along with elevation, which is a geographically localized phenomenon. Monthly PRISM precipitation and temperature data were calculated for each fire from 1989 to 2007 as a modeled indication of the actual precipitation and temperature for each site by calculating the average of all pixels within the burned perimeter. The monthly precipitation data were summed for the post-fire period for each fire, as the sum of the first year's precipitation $\left(P P T_{1 y r}\right)$, the first five years' $\left(P P T_{5 y r}\right)$ and the first 10 years' $\left(P P T_{10 y r}\right)$, to determine over which time period precipitation was most important. In similar fashion temperature data were evaluated over one, five, and ten year periods post-fire. Over the three periods monthly temperature extremes were summarized by determining the highest monthly maximum and lowest monthly minimum temperatures. As the data were summarized over successive time periods, the sample size of the variables declined, since fewer sites had a sufficient time-series to complete the summary. Thus the number of sites examined for one, five, and ten years were 115, 109, and 47 respectively. Elevation data (Elev) were obtained for each of the fires by averaging 10-m resolution pixels of the National Elevation Dataset [25] contained within the fire perimeter for each of the fires.

Local factors were evaluated through the use of regression and CART analyses. As with the regional factors, SLR was used to relate NDVI to each of the factors individually. With MLR, however, only one of each of the summed precipitation and temperature values at a time was tested in concert with elevation, resulting in the full model:

$$
\text { slope }=\beta_{0}+\beta_{1} P P T_{y r}+\beta_{2} M a x T_{y r}+\beta_{3} M i n T_{y r}+\beta_{4} \text { Elev }
$$

where $P P T_{y r}, M_{a x} T_{y r}$, and $M i n T_{y r}$ are the summaries of precipitation and temperature which had the most significant simple linear relationship to NDVI, either over one, five, or ten years post-fire.

\section{Results}

\section{1. $H_{1}$ : Evaluating post-fire regression slopes}

Visual interpretation of histograms for the post-fire slope of the NDVI time-series show evidence that, on average, NDVI slopes tend to be positive (Figure 2). A one sided t-test gave strong statistical support for this hypothesis $(\mathrm{p}<0.0001)$.

\subsection{H2: Evaluating Bailey's ecoregions}

The ANOVA of post-fire NDVI slope data showed no differences at the Domain scale $(\alpha=0.05)$, however differences were detected at the Division and Province levels (Figure 3). Provinces did not differ significantly within their respective Divisions, but only with Provinces in other Divisions. The Division level was deemed the appropriate level at which to evaluate differences in post-fire vegetation 
dynamics. Multiple two sample t-test comparisons showed that Division 16 (Table 1) was significantly different from all other Divisions, after adjusting for multiple comparisons.

Figure 2. Histogram of post-fire NDVI slopes within the burned perimeter for all fires evaluated. $98 \%$ of the slopes were positive.

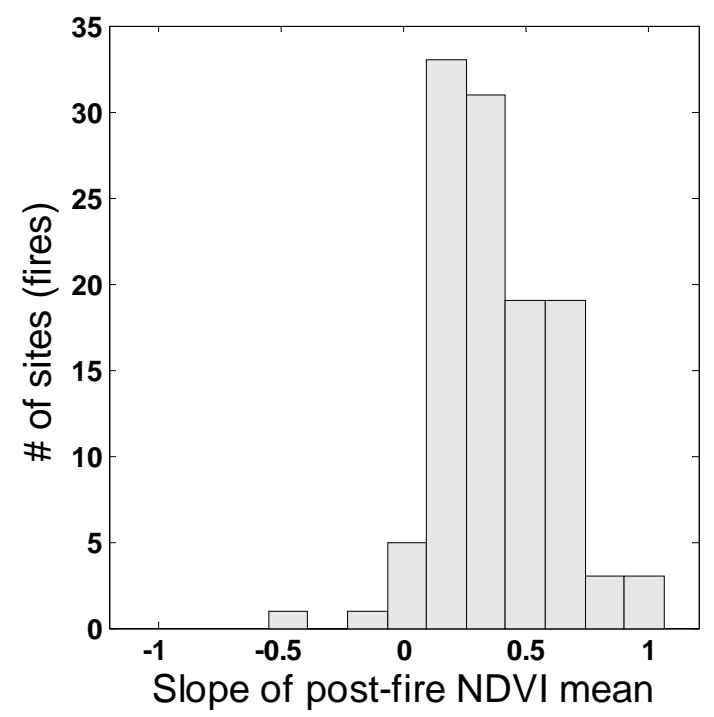

Figure 3. Boxplots illustrating the differences in post-fire NDVI slope across ecoregions at the Domain (a), Division (b), and Province (c) levels. The ecoregions indicated here are identified in Table 1. Boxes show the upper and lower quartiles, with the median marked with a line. Whiskers extend to 1.5 times the interquartile range, and outliers are indicated by a+. ANOVA analysis showed differences at the Division and Province levels, and CART analysis showed differences in regression slopes between Division classes 13, 14, 16 , and 28 and all other classes.
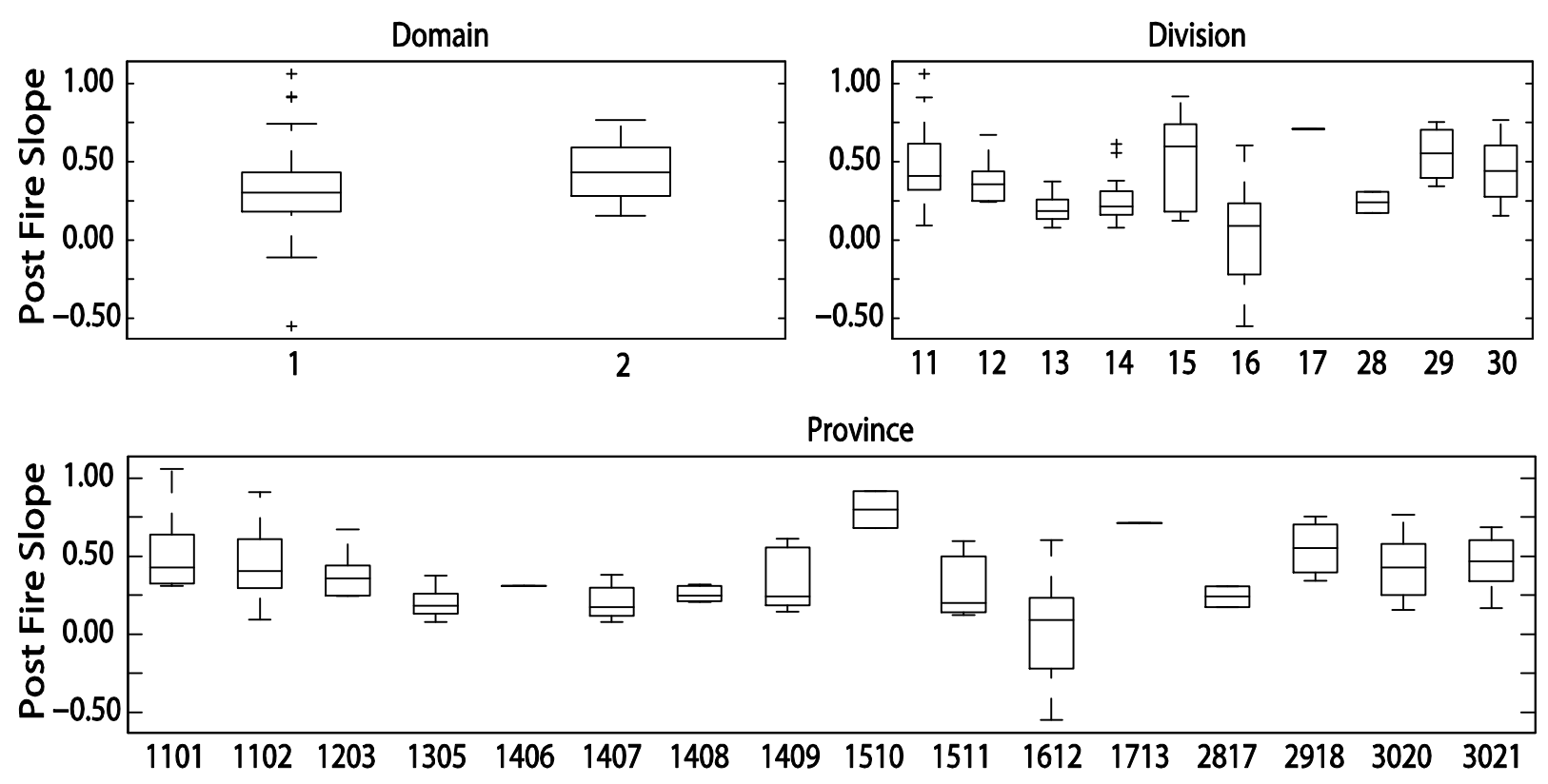


\subsection{H4: Evaluation of environmental factors}

Regression trees showed similar results to MLR analysis, hence the results are not repeated in detail. The one exception was the use of regression trees to test the inclusion of Bailey's ecoregion Divisions. This resulted in a tree that predicted lower post-fire NDVI slopes for Divisions 13, 14, 16, and 28 (Table 1; 0.214) than for the other Divisions (0.453). After accounting for ecoregion Division (the first branch), no other regional factors predicted NDVI slope. Visual examination of Division boxplots (Figure 3(b)) suggests similar delineations between Divisions as noted by the CART analysis.

CART separations based on ecoregion Divisions were mapped and combined with the post-fire NDVI slope data for each fire location (Figure 4). A two sample t-test showed that the regions were significantly different $(\alpha<0.05)$ for all of the environmental variables tested, which indicated that Divisions 13, 14, 16, and 28 had smaller post-fire NDVI slopes, lower temperatures, and higher precipitation (Figure 5).

Recall that we defined regional and local factors separately, regional factors including long-term average climate data, and local factors consisting of monthly climate data and elevation. SLR relating post-fire NDVI slopes to the regional factors individually showed significant relationships between post-fire NDVI slope and $\operatorname{MaxT}(\mathrm{p}=0.0002), \operatorname{MinT}(\mathrm{p}=0.0107)$ and $P P T_{\text {summer }}(\mathrm{p}=0.0131)$ (Figure 6). The stepwise MLR procedure selected only $\operatorname{Max} T\left(\mathrm{p}=0.0002\right.$, adjusted $\mathrm{R}^{2}=0.11$; Table 3$)$.

SLR for each of the local variables separately showed varying results depending on the period of summary for the precipitation and temperature data (Figure 7). Precipitation was significantly related to post-fire NDVI slope only when summed over 10 years. Minimum temperature was a significant predictor of NDVI slope only in the first year post-fire, while maximum temperature was significant over one and five years post-fire.

Two full models were tested using the stepwise procedure, one using summaries for the first year, and one using summaries over the first ten years. For the first year, only $M i n T_{1 y r}$ emerged as a significant predictor, with higher post-fire NDVI slopes occurring with increases in $M i n T_{1 y r}$ (adjusted $\mathrm{R}^{2}=0.075, \mathrm{p}=0.0018$ ). For the model with ten years' summarized data, Elev and $P P T_{10 y r}$ contributed significantly to the relationship (adjusted $\mathrm{R}^{2}=0.368, \mathrm{p}<0.0001$ ). Using this reduced model, post-fire NDVI slope decreased with increases in elevation, and increased with increases in 10 years' accumulated precipitation. 
Figure 4. Map of study region, showing fire locations. Size of circles indicates magnitude of the post-fire NDVI slope (higher slopes indicated by larger circles). Bailey's ecoregion Divisions are outlined in white. CART analysis estimated that Divisions 13, 14, 16, and 28 have a lower post-fire NDVI slope (0.214) than the remaining Divisions (0.453).

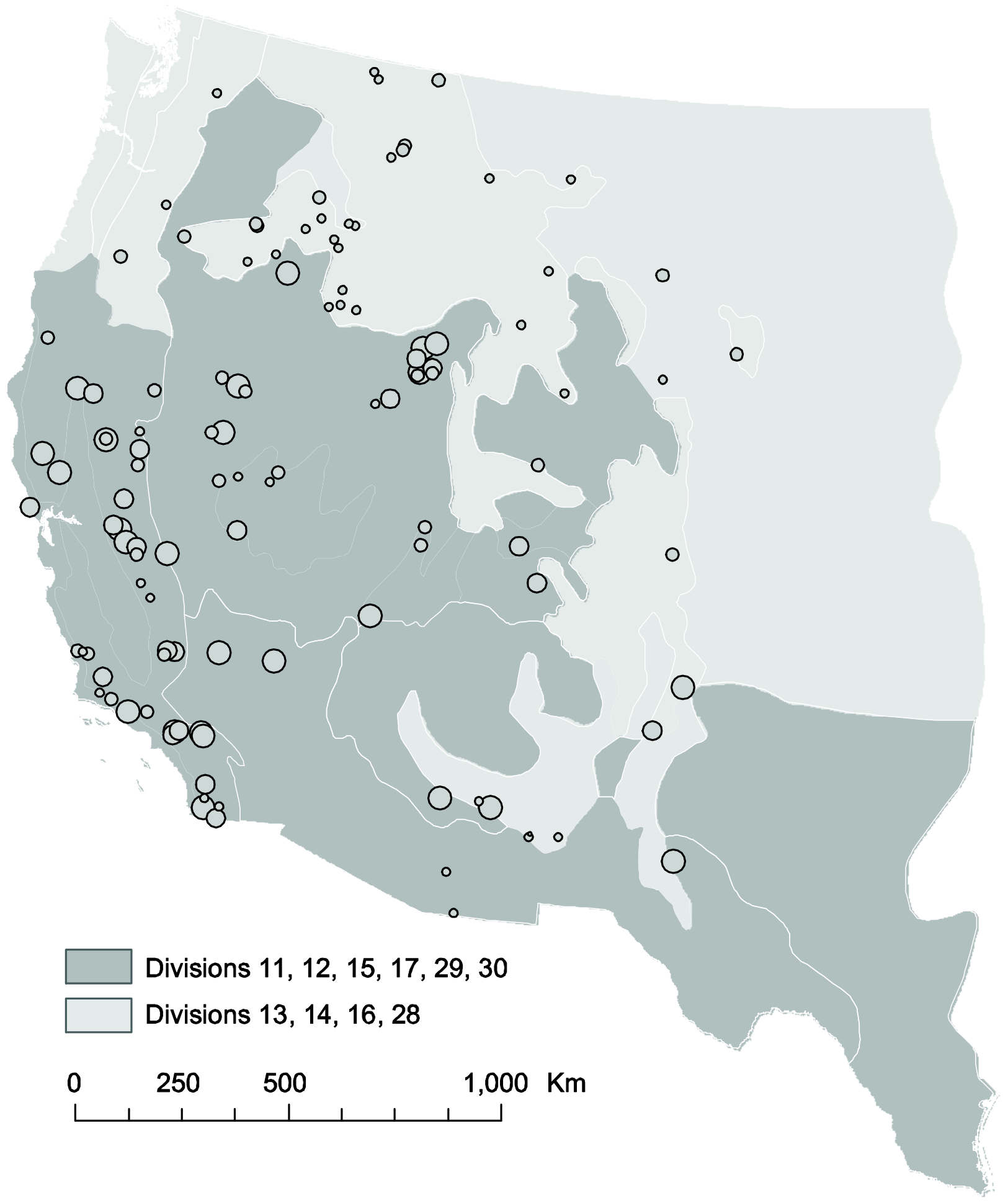


Figure 5. Boxplots showing the differences in regional scale factors and elevation between the two regions delineated using CART analysis. Plots for region one indicate values for Divisions 13, 14, 16, and 28, and plots for region two indicate values for all other Divisions. Significance of the difference between each factor was tested using a t-test with unequal sample sizes, p-values are shown in the lower right corner of each plot. HiMax refers to the annual maximum of the monthly maxima for the 30 year average temperature, and LoMin refers similarly to the minimum of the monthly minima.
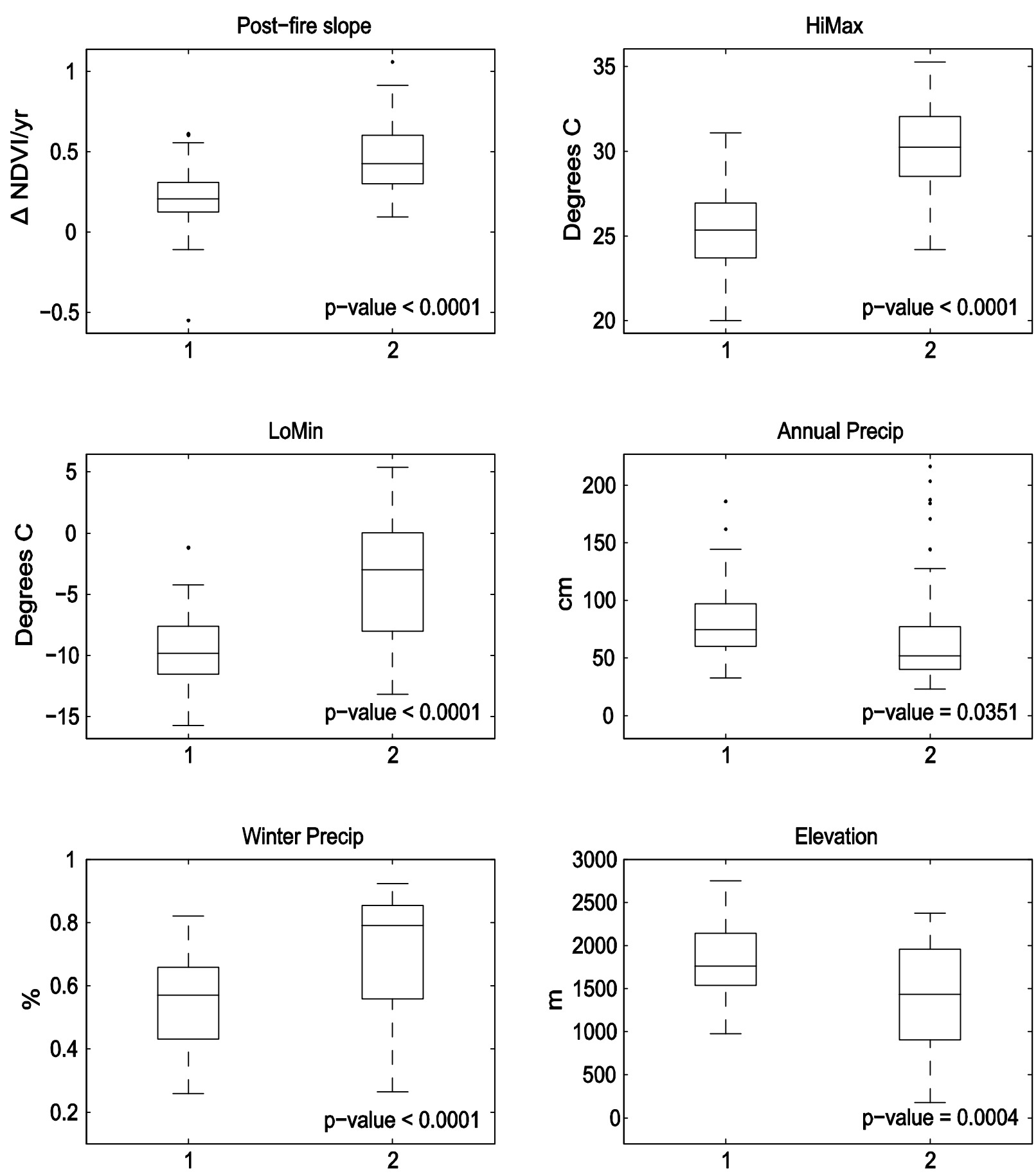
Figure 6. Scatterplots and least squared regression lines for the relationship between regional-scale factors and post-fire NDVI $(\Delta$ NDVI).
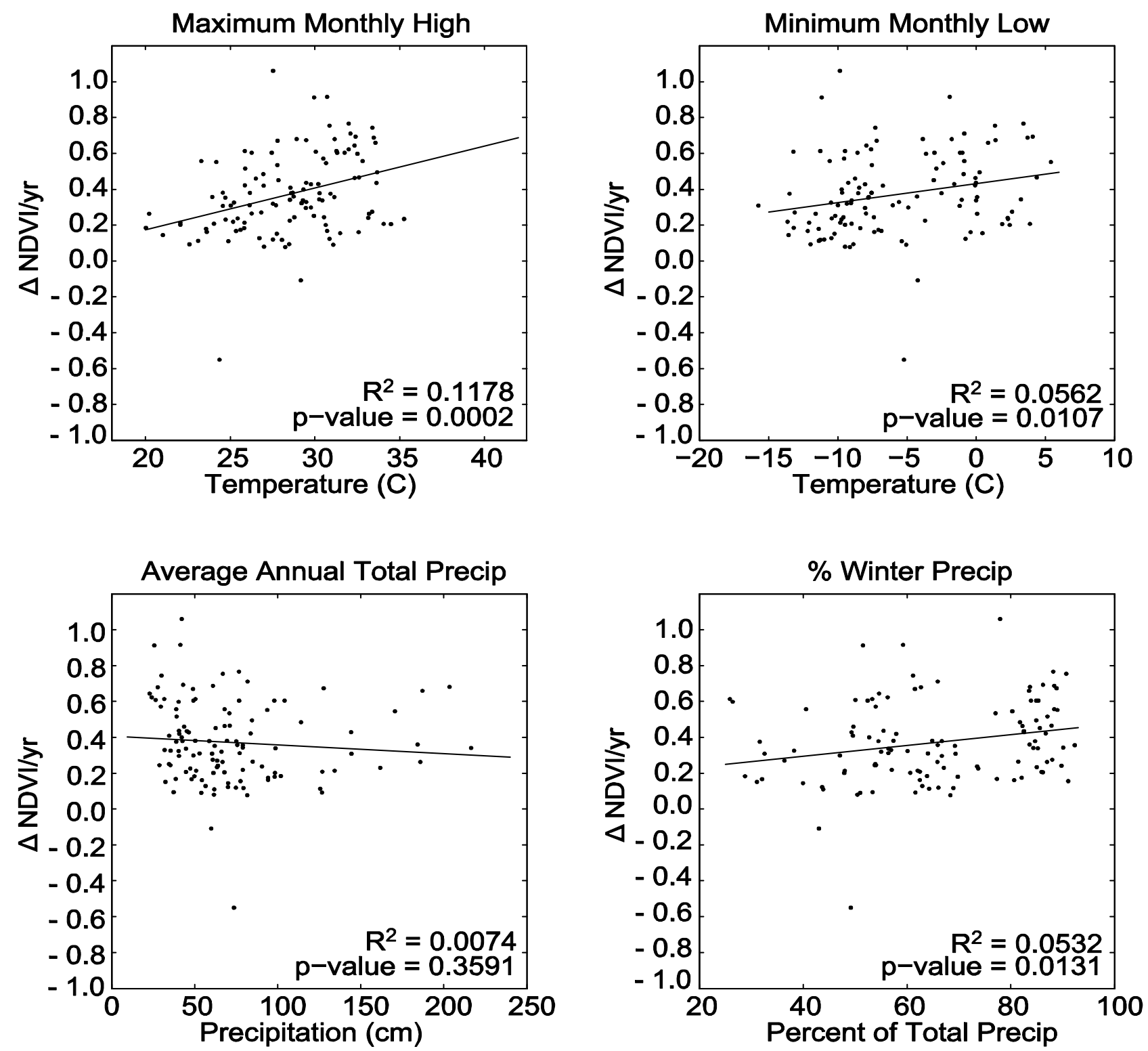
Figure 7. Scatterplots and least squared regression lines for the relationship between local-scale factors and post-fire NDVI slopes.
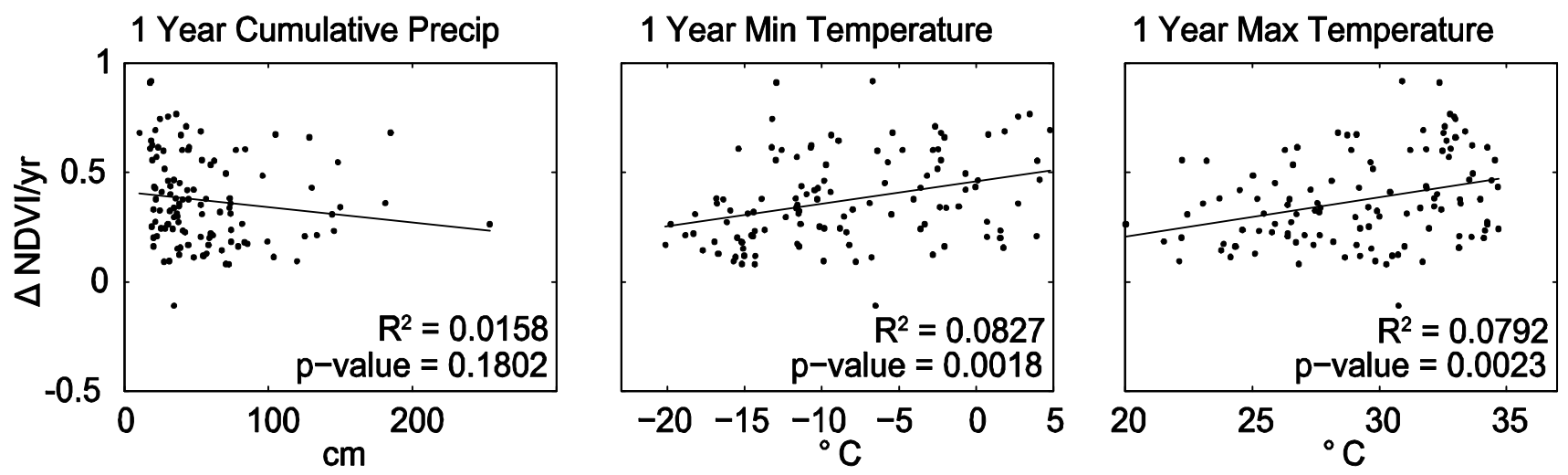

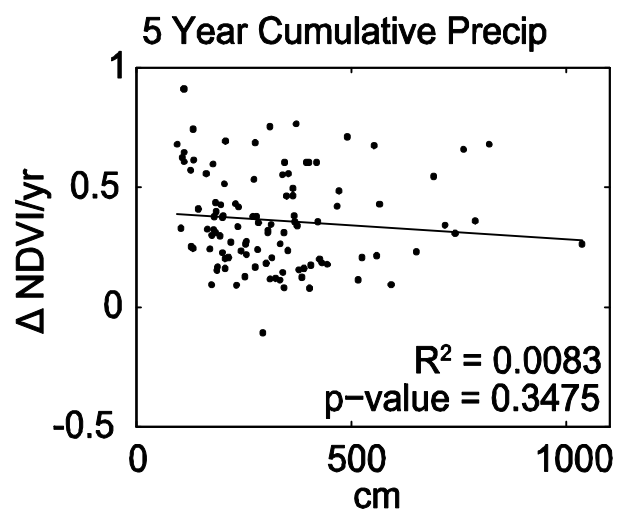

5 Year Min Temperature

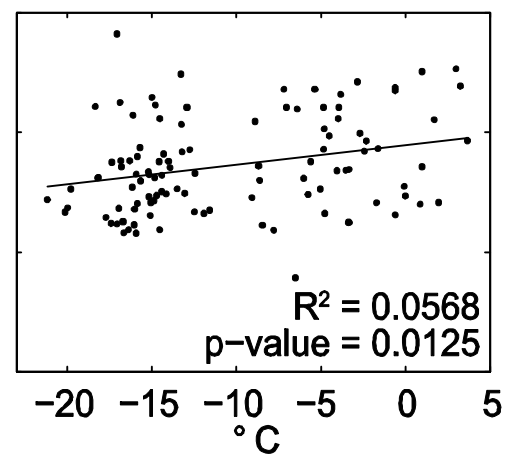

10 Year Min Temperature

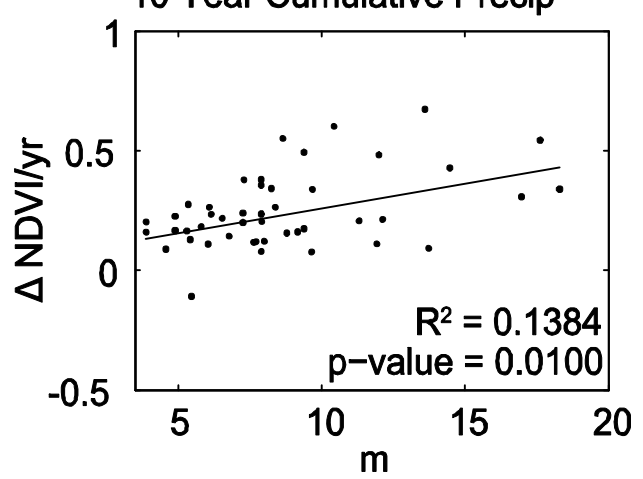

Elevation
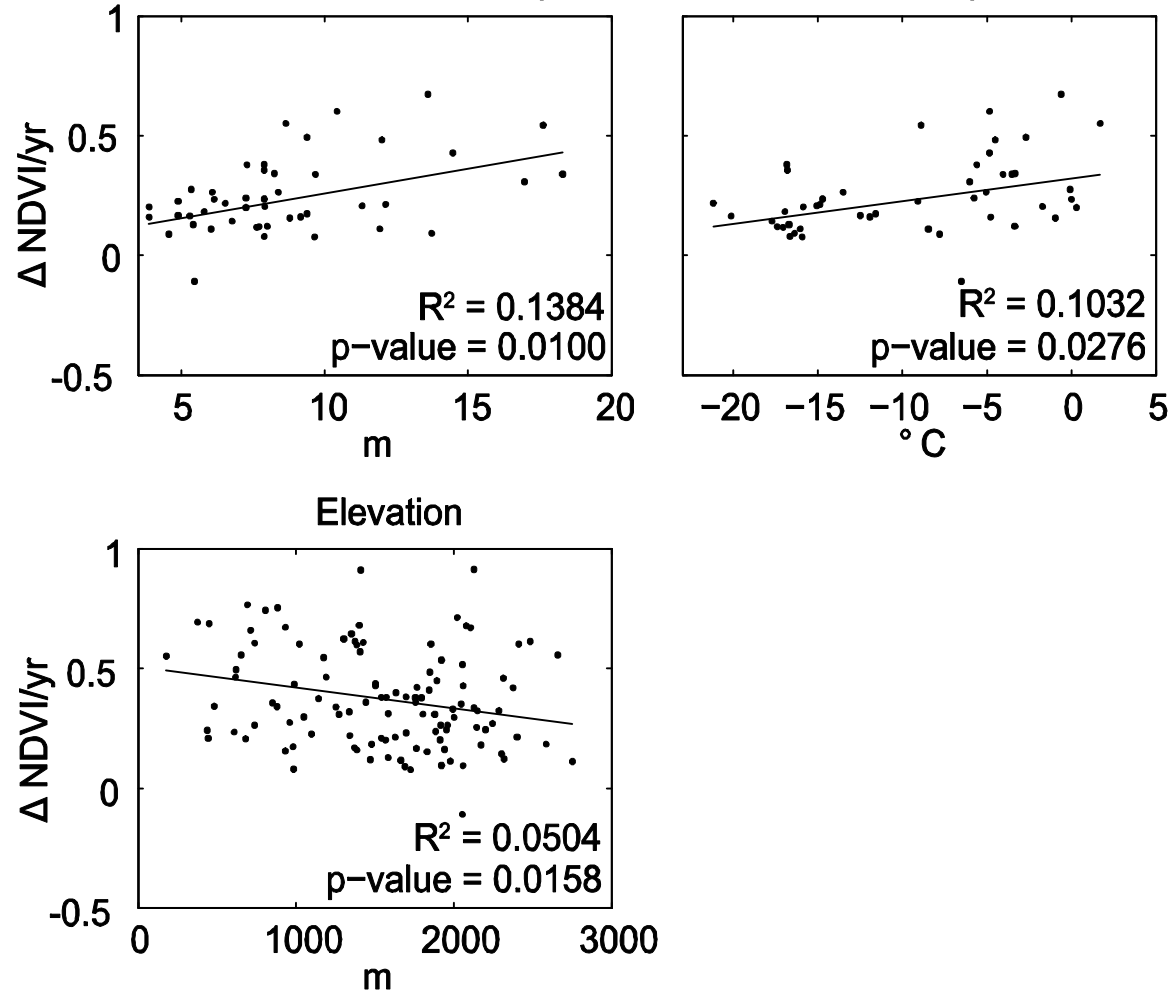

5 Year Max Temperature

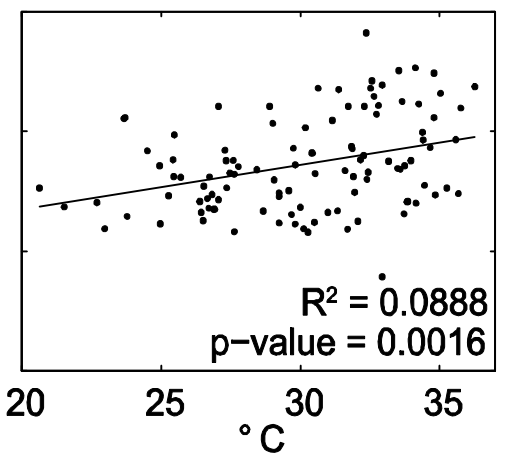

10 Year Max Temperature

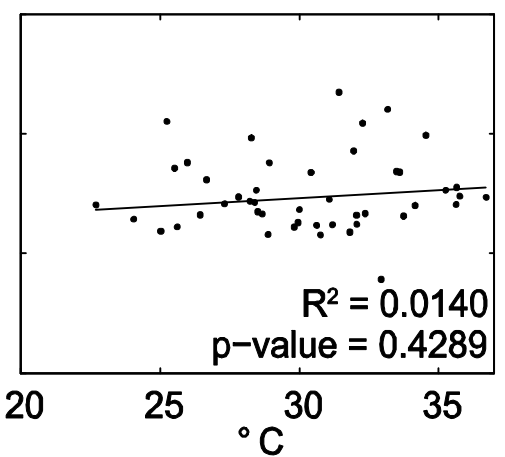

35 


\section{Discussion}

\subsection{Selection of burned areas}

While our methods provided a sufficient number of fires for our analysis, the majority of fire records were not used due to insufficient evidence of a burned area or post-fire trend. Of the 3,198 large fires selected from the DRI database, only 443 showed evidence of a burn scar, and only 115 had significant post-fire regression slopes. This small number of sampled fires is due to the rigorous selection criteria we used in selecting fires, as well as uncertainties in the datasets used to assess burned areas. First, as mentioned in the introduction, the DRI database is acknowledged to have errors [20].

Second, the use of a high z-score for the detection of burned area is rigorous, selecting only pixels that have changed substantially. We set the z-score threshold high to avoid including unburned pixels in our analysis. The challenge of selecting an appropriate z-score is highlighted in Figure 8, where some pixels within the burn perimeter have lower values than some unburned pixels. Using a high z-score eliminated these pixels from the analysis, however they were likely burned at lower severity. This approach ensured a sample of only burned pixels, however it would not be valuable for the detection of burned areas in general.

A third factor leading to a smaller sample of fires was the challenge of establishing statistically significant post-fire regression slopes. This difficulty could be due to four potential causes, most likely a combination of all four. First, NDVI data are susceptible to contamination by cloud and snow cover. Changes in the yearly duration of snow or cloud cover can cause shifts in integrated NDVI, leading to departures from a trend of increasing post-fire NDVI.

Second, the AVHRR MVC data record is comprised of data acquired by four different satellite sensors over a period of 19 years and processed using seven different radiometric calibration methods [15]. Changes in sensors and calibration methods over the course of the record result in differences in derived reflectance data and therefore NDVI over time [26], which add variability to the integrated NDVI used to indicate post-fire productivity. This variability makes it difficult to establish significant post-fire slopes in NDVI, resulting in a type II statistical error.

Third, significant post-fire NDVI slopes may be difficult to establish due to natural variations in the post-fire vegetation growth. While an ecosystem may be generally increasing in productivity over a number of years, changes in seasonal environmental conditions can dramatically influence annual production. This may be important for later fires in our analysis, with a limited number of post-fire years from which to evaluate trends. A single year of drought in a five year time-series may add sufficient variability to the time-series that the slope is not statistically differentiable from zero.

Finally, the true slope of the post-fire NDVI time-series may be zero. Some environments may recover rapidly from fire in a single year. Annual grasslands can generate a substantial amount of fine fuel, burn, and re-establish in the course of a single year [27]. Because the statistical test used to establish significance was a test for a difference from a zero slope, zero slope trends were eliminated from the analysis. 
Figure 8. Rodeo-Chediski fire burned perimeter (gray) as defined by the US Forest Service, compared to the area identified for analysis (black), overlaid on the search area of $1 \mathrm{~km}^{2} \mathrm{z}$-score pixels, as calculated using formula 1 . This highlights the challenge of using the z-score threshold to identify a burned area precisely for areas burned at lower severity. Some pixels within the burned perimeter are similar in $z$-score value to those outside the perimeter, such that using a more lenient threshold would result in the inclusion of unburned pixels. For our analysis here we wanted to ensure a sample of only burned pixels. Also, the burned area to the left of the regions selected for analysis was excluded, since it resulted in a smaller region of contiguous pixels above the z-score threshold than the area selected. It was eliminated in order to avoid over-representing dynamics for any single fire, since its inclusion would have resulted in two samples for the same fire.

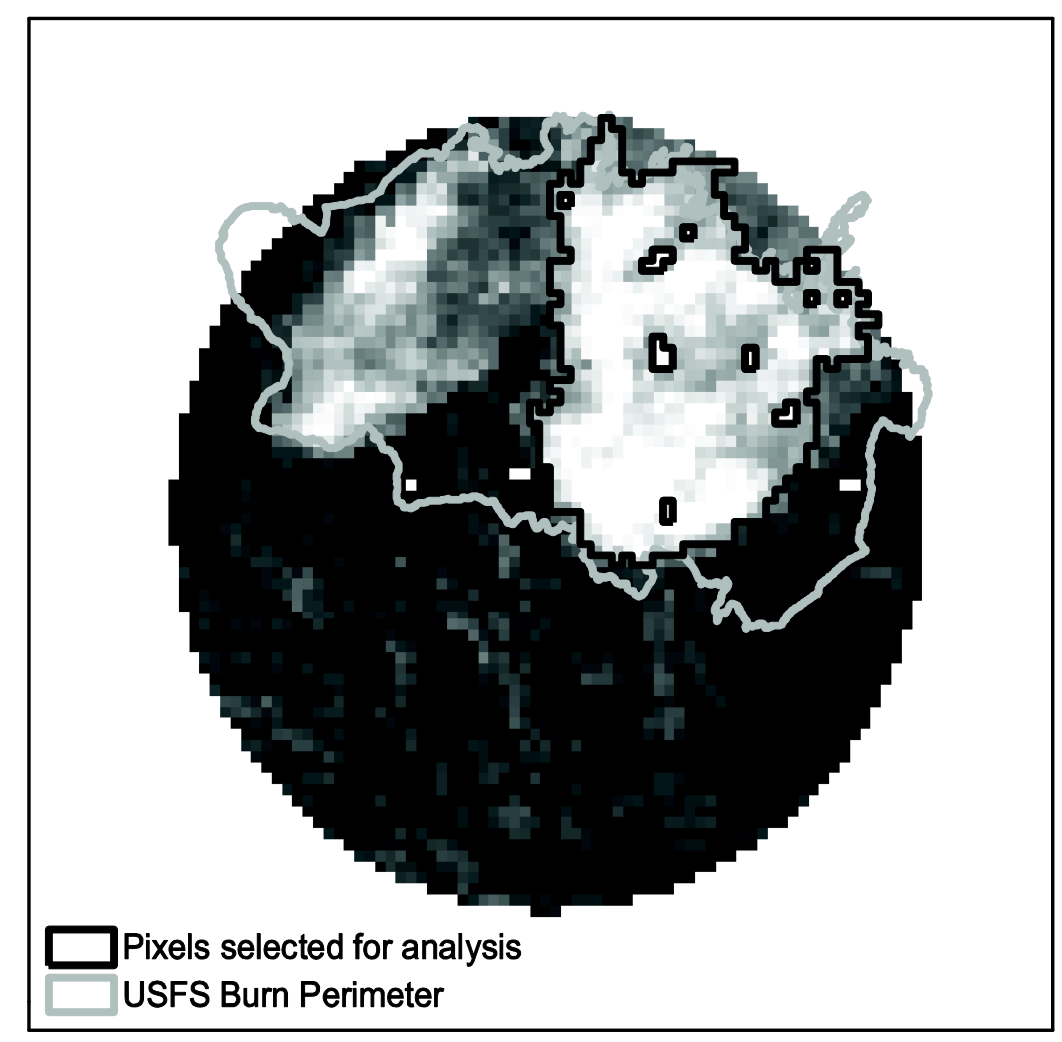

\subsection{Evaluating trends in post-fire vegetation}

In spite of difficulties in detecting burned areas and establishing significant post-fire trends, the AVHRR time-series data used in these analyses provided evidence for increases in post-fire NDVI over time $\left(\mathrm{H}_{1}\right)$. Our results support the results of others [16,17], showing strong evidence for positive trends in post-fire NDVI, with only two records out of 115 showing a negative post-fire slope. Of these, one had a small post-fire slope $(-0.108)$, potentially influenced by clouds or changes in sensor or calibration. The other record was burned in 1995, and again in 2002, resulting in a negative slope across the record since the 1995 burn. It is possible that other sites burned more than once over the period of record and went unnoticed. This result would have the effect of reducing the regression slope of the post-fire NDVI, making it either lower than it would otherwise be, or resulting in a 
non-significant regression slope, thus removing the fire from the analysis. Observation of the data set indicates that this occurrence was rare, and had little effect on the outcome of the analysis.

\subsection{Post-fire trends across ecoregions}

The spatial contiguity of Provinces selected by the CART analysis (Figure 4) supports the idea that there are differences in rates of post-fire change in productivity across regions. Amiro et al. [16] found differences in post-fire changes in NPP between ecoregions, however they did not test for significance among these differences. Hicke et al. [17] made qualitative assessment of differences in post-fire recovery times between ecoregions, but small sample sizes precluded statistical evaluation. Similarly, we found it challenging to use pairwise multiple comparisons to evaluate differences in post-fire NDVI, probably also due to insufficient sample sizes. We therefore found CART to be helpful, since it creates binary divisions to group ecoregions with similar post-fire trends together, rather than evaluating the differences between ecoregions one at a time.

Descriptive statistics of environmental differences between the two regions identified using the CART analysis provided insights regarding which environmental factors may be responsible for the distribution of post-fire vegetation trends, although they by no means provide a causal link.

\subsection{Environmental drivers of post-fire productivity}

Comparisons of regions delineated by the CART analysis (Figure 5), regression between post-fire NDVI and $30 \mathrm{yr}$ temperature data (Figure 6), and regression using shorter term weather data (Figure 7) all indicated that rates of change in post-fire NDVI increased with increases in temperature. Minimum temperature data showed the most consistent relationship to post-fire NDVI, showing significant contributions to all SLR and MLR models for which it was tested. The exception to this was that of the model tested for ten year summarized local-scale factors (Table 2). This model:

$$
\text { NDVIslope }=\beta 0+\beta 1 \text { PPTyr } 10+\beta 2 \text { Elev }
$$

indicated that NDVI slope is lower at higher elevations. Elevation is not an environmental determinant to plant growth per se, but co-varies with precipitation and temperature. Precipitation typically increases with elevation, and our results generally showed increases in NDVI slope with higher levels of precipitation. Thus decreases in slope with increasing elevation are not likely due to a change in precipitation with elevation, but rather to changes in temperature, which tends to decrease at higher elevations. Further evidence that elevation may be serving as a proxy for temperature in this model is seen in that SLR relating NDVI slope with ten year minimum temperature shows a moderately significant relationship (Figure 7), which would likely be stronger with a larger sample size, as in the one year minimum temperature. This gives further evidence that minimum temperatures limit vegetation growth in the post-fire environment.

The relationship between precipitation and post-fire NDVI slope is not as consistent as that between temperature and NDVI slope. The comparison between regions delineated using CART shows moderate evidence $(p=0.035)$ that regions with higher precipitation have lower post-fire NDVI slopes. SLR and MLR using 30 year average annual precipitation, and one and five year post-fire accumulated precipitation, show no significant relationships between precipitation and post-fire NDVI. Ten year accumulated precipitation shows strong evidence of higher post-fire NDVI slopes with 
accumulations of precipitation, both using SLR and in combination with elevation, as discussed above (Equation 5). This suggests that post-fire production is higher with higher precipitation, especially when coupled with higher temperatures. The ten year accumulation of precipitation may indicate that post-fire vegetation dynamics are sensitive to changes in precipitation over the entire course of the post-fire response.

It is intuitive that vegetation growth after a fire event is limited by low (freezing) temperatures and limited precipitation. This study establishes that these forces are important determinants across large areas and are to some degree independent of the fine-scale environmental conditions most often associated with post-disturbance vegetation dynamics. While the portion of variability explained by broad-scale factors is small, exhibiting small coefficients of determination $\left(\mathrm{R}^{2}\right)$, the contribution of these factors to predictions of post-fire vegetation trends was statistically significant $(\alpha<0.05)$. This indicates that while much of the post-disturbance vegetation dynamics at a site are explained by fine-scale site specific determinants such as vegetation or soil, broad-scale factors also play an important role. Fine-scale factors contribute to vegetation dynamics only within the confines set by the higher level controls of temperature and precipitation, thus changes in these parameters represent changes to the framework within which post-disturbance vegetation dynamics occur. The response of lower level functions to changes in higher level constraints is often non-linear, thus small changes in precipitation or temperature could lead to large or unexpected responses at the local scale [28]. This research indicates that broad-scale climate drivers are responsible for differences in rates of post-fire vegetation regeneration, however further work is needed to evaluate the interaction between fine scale factors that result in deviations from post-fire response due to broad-scale climatic drivers.

A local environmental factor that could have reasonably been added to our analysis, but which we omitted, is land cover type, since pre-disturbance land cover influences post-disturbance ecosystem trajectories. We did not include land cover in this study due to the difficulty of getting a consistent land cover product that could be utilized across the entire region for all fires. Since land cover is dynamic, it would have been important to have a land cover map within a few years prior to each of the fires evaluated. Since the fires spanned a period of 15 years, this was not possible. In spite of this omission, both local and regional factors influence post-fire productivity, indicating that the results shown here are not restricted to particular land cover types.

\section{Conclusions}

We show evidence in this study that rates of post-fire vegetation regrowth were influenced across the western US by differences in temperature and precipitation. Sites with higher minimum annual temperatures had faster rates of regeneration. Higher rates of sustained post-fire regeneration occurred with increases in precipitation for at least ten years post-fire. These findings have ramifications for post-fire management in a scenario of shifting high-level drivers of ecosystem function, where changes in climate will result in shifts in post-fire vegetation dynamics. These dynamics may be linked to feedbacks in the climate system, with changes in climate leading to changes in disturbance regimes [6], as well as changes in post-disturbance dynamics. These altered ecosystem dynamics influence the global energy budget through changes in carbon exchange and surface albedo [18]. Our study 
re-emphasized the value of using post-fire time-series vegetation data. We concur with Kasischke and French [29] that although the AVHRR time-series presents challenges to long-term vegetation monitoring, the long time-series of vegetation data is invaluable for monitoring global vegetation dynamics. Research of this type should be pursued with newer sensors that provide better spectral continuity, such as the Moderate Resolution Imaging Spectroradiometer (MODIS), as these sensors accumulate a longer time-series.

Further research should be pursued in order to elucidate the relationships between ecosystem controls of post-fire vegetation dynamics. Work has been done to evaluate the importance of local-scale drivers [9,11]. We have established here the importance of higher level controls such as climate. A remaining area of research is to develop a framework whereby local-scale processes are nested within higher level controls and evaluated based on an understanding of the relationships between levels.

\section{Acknowledgments}

We thank Timothy Brown and DRI for their provision of the federal lands wildfire database. We thank Steve Yool for his insights on using AVHRR time-series to delineate burned areas. Steve Archer, Alfredo Huete, Barron Orr, and Wim van Leeuwen provided feedback on earlier versions of this manuscript.

\section{References}

1. Pickett, S.T.A.; White, P.S. The Ecology of Natural Disturbances and Patch Dynamics; Academic Press: Orlando, FL, USA, 1985; p. 472.

2. O’Neill, R.V.; DeAngelis, D.L.; Waide, J.B.; Allen, T.F.H. A Hierarchical Concept of Ecosystems; Princeton University Press: Princeton, NJ, USA, 1986.

3. Overpeck, J.T.; Rind, D.; Goldberg, R. Climate-induced changes in forest disturbance and vegetation. Nature 1990, 343, 51-53.

4. Westerling, A.L.; Hidalgo, H.G.; Cayan, D.R.; Swetnam, T.W. Warming and earlier spring increase western US forest wildfire activity. Science 2006, 313, 940-943.

5. Flannigan, M.D.; Stocks, B.J.; Wotton, B.M. Climate change and forest fires. Sci. Total Environ. 2000, 262, 221-229.

6. Dale, V.H.; Joyce, L.A.; McNulty, S.; Neilson, R.P.; Ayres, M.P.; Flannigan, M.D.; Hanson, P.J.; Irland, L.C.; Lugo, A.E.; Peterson, C.J.; Simberloff, D.; Swanson, F.J.; Stocks, B.J.; Wotton, B.M. Climate change and forest disturbances. Bioscience 2001, 51, 723-734.

7. Easterling, W.; Apps, M. Assessing the consequences of climate change for food and forest resources: A view from the IPCC. Climate Change 2005, 70, 165-189.

8. IPCC. Climate Change 2007: Synthesis Report; Intergovernmental Panel on Climate Change: Valencia, Spain, 2007; p. 52.

9. DeBano, L.F.; Neary, D.G.; Ffolliott, P.F. Fire's Effects on Ecosystems; John Wiley \& Sons: New York, NY, USA, 1998.

10. Neary, D.G.; Klopatek, C.C.; DeBano, L.F.; Ffolliott, P.F. Fire effects on belowground sustainability: A review and synthesis. Forest Ecol. Manage. 1999, 122, 51-71. 
11. Turner, M.G.; Romme, W.H.; Gardner, R.H. Prefire heterogeneity, fire severity, and early postfire plant reestablishment in subalpine forests of Yellowstone National Park, Wyoming. Int. J. Wildland Fire 1999, 9, 21-36.

12. Goward, S.N.; Tucker, C.J.; Dye, D.G. North-American vegetation patterns observed with the NOAA-7 advanced very high-resolution radiometer. Vegetatio 1985, 64, 3-14.

13. Prince, S.D.; Goetz, S.J.; Goward, S.N. Monitoring primary production from earth observing satellites. Water Air Soil Pollut. 1995, 82, 509-522.

14. Reed, B.C.; Brown, J.F.; Vanderzee, D.; Loveland, T.R.; Merchant, J.W.; Ohlen, D.O. Measuring phenological variability from satellite imagery. J. Veg. Sci. 1994, 5, 703-714.

15. Eidenshink, J. A 16-year time series of $1 \mathrm{~km}$ AVHRR satellite data of the conterminous United States and Alaska. Photogramm. Eng. Remote Sensing 2006, 72, 1027-1035.

16. Amiro, B.D.; Chen, J.M.; Liu, J. Net primary productivity following forest fire for Canadian ecoregions. Can. J. Forest Res. 2000, 30, 939-947.

17. Hicke, J.A.; Asner, G.P.; Kasischke, E.S.; French, N.H.F.; Randerson, J.T.; Collatz, G.J.; Stocks, B.J.; Tucker, C.J.; Los, S.O.; Field, C.B. Postfire response of North American boreal forest net primary productivity analyzed with satellite observations. Glob. Change Biol. 2003, 9, 1145-1157.

18. Goetz, S.J.; Fiske, G.J.; Bunn, A.G. Using satellite time-series data sets to analyze fire disturbance and forest recovery across Canada. Remote Sens. Environ. 2006, 101, 352-365.

19. Bailey, R.G. Ecosystem Geography; Springer-Verlag: New York, NY, USA, 1996.

20. Brown, T.J.; Hall, B.L.; Mohrle, C.R.; Reinbold, H.J. Coarse Assessment of Federal Wildland Fire Occurrence Data; Report for the National Wildfire Coordinating Group; CEFA Report 02-04; Program for Climate, Ecosystem and Fire Applications, Desert Research Institute: Reno, NV, USA, 2002; p. 30.

21. Yool, S.R. Enhancing fire scar anomalies in AVHRR NDVI time-series data. Geocarto Int. 2001, 16, 5-12.

22. Ramsey, F.L.; Schafer, D.W. The Statistical Sleuth: A Course in Methods of Data Analysis; Duxbury Press: New York, NY, USA, 1997; pp. 154-155.

23. Daly, C.; Neilson, R.P.; Phillips, D.L. A statistical topographic model for mapping climatological precipitation over mountainous terrain. J. Appl. Meteorol. 1994, 33, 140-158.

24. Breiman, L.; Friedman, J.; Stone, C.J.; Olshen, R.A. Classification and Regression Trees; Chapman \& Hall: Boca Raton, FL, USA, 1993.

25. Gesch, D.; Oimoen, M.; Greenlee, S.; Nelson, C.; Steuck, M.; Tyler, D. The National Elevation Dataset. Photogramm. Eng. Remote Sensing 2002, 68, 5-11.

26. van Leeuwen, W.J.D.; Orr, B.J.; Marsh, S.E.; Herrmann, S.M. Multi-sensor NDVI data continuity: Uncertainties and implications for vegetation monitoring applications. Remote Sens. Environ. 2006, 100, 67-81.

27. D'Antonio, C.M.; Vitousek, P.M. Biological invasions by exotic grasses, the grass fire cycle, and global change. Ann. Rev. Ecol. Syst. 1992, 23, 63-87.

28. Holling, C.S. Cross-scale morphology, geometry, and dynamics of ecosystems. Ecol. Monogr. 1992, 62, 447-502. 
29. Kasischke, E.S.; French, N.H.F. Constraints on using AVHRR composite index imagery to study patterns of vegetation cover in boreal forests. Int. J. Remote Sens. 1997, 18, 2403-2426.

(C) 2010 by the authors; licensee MDPI, Basel, Switzerland. This article is an open access article distributed under the terms and conditions of the Creative Commons Attribution license (http://creativecommons.org/licenses/by/3.0/). 